\title{
The Effects of Chlorcyclizine-Induced Glycosaminoglycan Alterations on Palatal Mesenchyme-Basal Lamina Relationships in the Mouse
}

\author{
LINDA L. BRINKLEY AND JOYCE MORRIS-WIMAN \\ Department of Anatomy and Cell Biology, University of Michigan Medical \\ School, Ann Arbor, Michigan 48109
}

\begin{abstract}
The relationships of mesenchymal cells to the basal lamina underlying regions of the palatal-shelf epithelium that are known to increase in cell density during shelf reorientation are quantitatively different from those of cells underlying neighboring regions that do not increase in cell density. Chlorcyclizine-induced alterations of the extracellular matrix were used to investigate the possible contribution of extracellular matrix to these differences. Chlorcyclizine causes hyaluronate and the chondroitin sulfates to be degraded into pieces with smaller molecular weights and lower charge densities, with little or no effect on their synthesis, and also results in cleft palate. Pregnant CD-1 mice were gavaged with chlorcylizine on days $10.5,11.5$, and 12.5 of gestation, and the fetuses were harvested on day 13.5. Some palatal shelves were excised immediately and fixed for electron microscopy; other heads were partially dissected and incubated for $4 \mathrm{hr}$ prior to fixation. In normal heads differences in mesenchymal cell configurations are detectable after $4 \mathrm{hr}$ in vitro. Electron micrographs were taken of the epithelial-mesenchymal interface in nasal and oral regions that increased in epithelial cell density and in nasal and oral regions which did not. Several variables of mesenchymal cell configuration were measured in a 500-nm-wide zone delimited on photographic prints. Chlorcyclizine-induced glycosaminoglycan alterations resulted in quantifiable, region-specific differences in mesenchymal cell relationships to the basal lamina and in the ultrastructural appearance of the zone immediately subjacent to the basal lamina. These results suggest that the epithelial-mesenchymal interface and sublaminar zone of the nasal and oral regions as well as their active and inactive segments may be constitutively different.
\end{abstract}

Two regions of the epithelial perimeter of secondary palatal shelves, one on the future nasal surface, the other on the oral, show significant changes in epithelial cell packing during the course of shelf reorientation in contrast with neighboring inactive regions which do not (Brinkley, 1984). In addition, in those regions where epithelial cell density increases, mesenchymal cells immediately subjacent to the basal lamina display quantitatively different relationships to it than do the cells underlying neighboring regions in which cell density does not change. Qualitative differences in the extracellular matrix of the sublaminar regions are also observed (Brinkley, 1986).

Extracellular matrices play major roles in cell behavior. They serve not only as structural, supporting frameworks but are also an integral part of cell surfaces (see Trelstad, 1984, for review). Remodeling of the basal lamina by mesenchymal cells has also been shown to play a role in changing epithelial cell architecture to give rise to branching morphogenesis (Bernfield et al, 1984). The extracellular matrix of the palatal shelves is

Received September 5, 1986. Accepted March 27, 1986. 
known to play an important role in shelf reorientation (Brinkley and Vickerman, 1982) and possibly in mesenchymal cell distribution across the palatal shelf (Brinkley and Bookstein, 1986). To investigate the involvement of extracellular matrix in epithelialmesenchymal cell interactions in these regions, drug perturbation was employed.

Just prior to reorientation, the extracellular matrix of the palatal shelves consists in large measure of glycosaminoglycans, principally hyaluronate and the chondroitin sulfates (Pratt et al, 1973). Chlorcyclizine (CHLR), an antihistaminic benzhydrylpiperazine compound, has been shown to cause hyaluronate and the chondroitin sulfates to be degraded into pieces with smaller molecular weights and lower charge densities, while having little or no effect on their synthesis (Wilk et al, 1978). When the compound is administered to pregnant mice, all of their offspring will have cleft palate and reduced mandibles (King, 1963; King et al, 1965). CHLR effects on the palatal shelves are distinct and regional. The anterior one-quarter is minimally affected and retains the ability to reorient. In contrast, the remainder of the shelf is reduced in cross-sectional area and unable to reorient in vivo or in vitro (Brinkley, 1980; Brinkley and Vickerman, 1982).

CHLR-induced alterations of the extracellular glycosaminoglycans of palatal shelves resulted in changes in the mesenchyme-basal lamina relationships in both nasal and oral regions of the epithelial mesenchymal interface as compared to controls. The active and inactive segments of both regions also showed distinctive responses to CHLR treatment.

\section{MATERIALS AND METHODS}

Specific details of all general methods used are given in the accompanying paper (Brinkley, 1986). Only information pertaining specifically to these studies will be given here.

\section{CHLR administration}

Sequential doses $(250 \mathrm{mg} / \mathrm{kg})$ of chlorcyclizine hydrochloride (Burroughs-Wellcome) were administered to pregnant CD-1 mice by gavage on gestational days 10.5, 11.5, and 12.5; this treatment regimen results in $100 \%$ cleft palate in the offspring (Brinkley and Vickerman, 1982). Each dose was delivered in a total volume of $0.5-\mathrm{ml}$ sterile tap water. Controls were gavaged with $0.5 \mathrm{ml}$ sterile tap water. Animals were cervically dislocated on day 13.5 gestation; and the fetuses, which were at a stage approximately $18 \mathrm{hr}$ prior to shelf reorientation, were harvested under sterile conditions for immediate fixation or incubation. Some partially dissected fetal heads were incubated for $4 \mathrm{hr}$ in a gassed, circulating culture system (Lewis et al, 1980). In normal heads of this age, initial shelf reorientation is detectable after $6 \mathrm{hr}$ in vitro. The 4 -hr time period was selected to detect events which precede reorientation. Details of the fetal staging, dissection, culture system, and conditions, and histological methods are as described in the accompanying paper (Brinkley, 1986).

\section{Sampling and data collection}

As in the previous study, the posterior part of the presumptive hard palatal shelf region was used. Regions of the nasal $(N)$ and oral (O) epithelial-mesenchymal interface which were known to be either active (A) or inactive (I) in terms of changes in epithelial cell packing during shelf reorientation were examined. Two to four shelves, each from a different individual and litter, were collected for each region (NA, NI, OA, OI) and incubation time $(0 \mathrm{hr}, 4 \mathrm{hr})$.

Collages of photographic prints $(\times 27,800)$ of electron micrographs of the epithelial-mesenchymal interface underlying ten to 12 consecutive epithelial cells were made. A 500. nm-wide zone immediately subjacent to the lamina densa was delineated (illustrated in Fig. 2, Brinkley, 1986). The following variables were measured with the aid of a bit linked to a Tektronix 4054 running a micrograph measurement program: cross-sectional size of each cell process and cell body with a nucleus lying within the measurement zone; point-to-point distance from the leading edge of each cell process to the lower edge of the lamina densa; run length of the lamina densa; and length of the lamina densa in intimate contact with cell processes or cell bodies-that is, where no measurable distance existed between the cell process and the lamina.

\section{Data analysis}

Data for cell-process size and distance from the basal lamina were subjected to the nonparametric Kruskal-Wallis median statistical test because of their non-normal distribution. Due to the variability in numbers of cell processes contacting the lamina densa, 
which ranged from zero to 23 (Fig. 5), the raw data are presented and no statistical test was employed.

\section{RESULTS}

Complete data on the sterile-water gavaged normal controls are presented in Brinkley (1986). Data from that control study are presented here only as required for comparisons. The following descriptions are of CHLRtreated animals.

\section{Ultrastructure}

Examples of the ultrastructural appearance of each of the four regions at $0 \mathrm{hr}$ and 4 $\mathrm{hr}$ incubation are shown in Figures 1 and 2, respectively.

The following three structures, visible when tannic acid is used in the fixative, were observed in all regions: a lamina lucida traversed by fine filaments, a compacted lamina densa, and a filamentous sublaminar layer attached to it. The sublaminar layer was composed of tannic-acid-precipitable material (TAPM), presumably glycosaminoglycans and glycoproteins (Singley and Solursh, 1980, 1981), $\sim 20$-nm filaments that sometimes bridged between the lamina densa and cell processes, and collagen. In both nasal regions a narrow band of TAPM was observed with prominent $\sim 20$-nm filaments projecting from the lamina densa into the mesenchyme. These filaments were most prominent in NA regions (Fig. 1A). The integrity of the lamina densa was sometimes disrupted, and occasionally epithelial-mesenchymal contact was seen (Fig. 1B). Although collagen was observed in both nasal regions, the NI regions contained more. OA regions were characterized by many small processes close to the lamina densa (Fig. 1C); large collagen deposits were also visible. OI regions had occasional patches where the basal laminar structure was indistinct, but nothing else unique was observed.

After 4-hr incubation considerbly more sublaminar TAPM was visible in NA, NI, and OI regions. Especially in the NA regions (Fig. 2A), collagen fibrils were often seen enmeshed in a network of TAPM and $-20-\mathrm{nm}$ filaments. The filaments were also visible in the other regions, but to a lesser extent. In NI regions, the amount of TAPM was markedly increased not only in the sublaminar zone but also between cell processes. The OA regions had smaller cell processes which were often farther from the lamina densa than at
$0 \mathrm{hr}$. OA and OI regions differed in the density of sublaminar material, with the latter displaying greater density.

\section{Number of cell processes}

Prior to incubation, both nasal and oral inactive segments had the same number of cell processes per unit area, and this did not change with incubation (Table 1). Active segments showed regional variation. In the nasal active region, the number of cell processes was less than in the inactive segments, while in the oral regions there were more processes in the active region. After incubation, the number of cell processes observed in the NA region, as in the inactive segments of both regions, was unchanged. The density of cell processes in the OA regions however, was reduced to the level observed in OI segments.

\section{Cell-process size}

Figure 3 displays the distribution of cellprocess sizes and the medians. NA and NI regions were significantly different from one another, as well as from their oral counterparts. The distributions of cell-process sizes in the NA and OI segments were equal to one another and significantly greater $(\mathrm{P}<.001)$ than that seen in their opposite segments. NI and OA segments also had similar size distributions. Incubation resulted in changes in all but the OA segments. The median sizes of cell processes in the NA and $\mathrm{OI}$ segments were significantly $(\mathrm{P}<.001) \mathrm{re}$ duced, while that of the NI segments was increased.

\section{Distance to basal lamina}

Cell processes were farther from the basal lamina in the nasal regions than in the oral ones (Fig. 4.). During incubation, cell processes in both oral regions moved farther from the basal lamina. Those in the NA regions were closer, while the NI regions remained unchanged.

\section{Cell process basal laminar contact}

The fraction of cell processes making direct contact with the basal lamina is shown in

TABLE 1. Cell processes per $1 \times 10^{6} \mathrm{~nm}^{2} *$

\begin{tabular}{llllll}
\hline \multirow{2}{*}{$\begin{array}{l}\text { Incubation } \\
\text { time }(\mathrm{hr})\end{array}$} & \multicolumn{2}{c}{ Nasal } & & \multicolumn{2}{c}{ Oral } \\
\cline { 2 - 3 } \cline { 5 - 6 } \cline { 6 - 7 } & Active & Inactive & & Active & Inactive \\
\hline 0 & 0.0016 & $\mathbf{0 . 0 0 2 5}$ & & 0.0044 & 0.0024 \\
\hline
\end{tabular}

*Values are means for the entire data sets. 

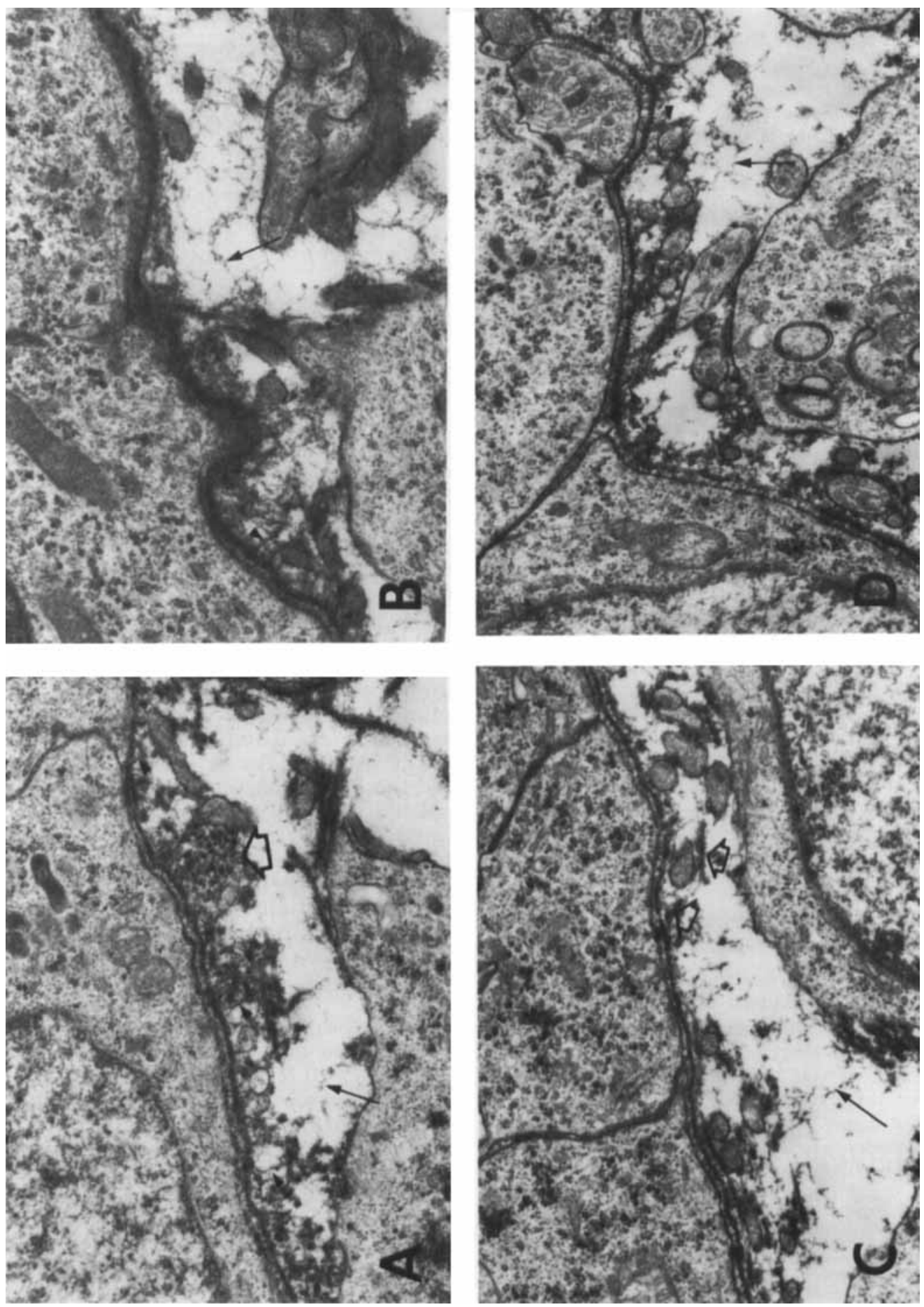
Table 2. The extent of contact made by each process is displayed in Figure 5.

No cell process made direct contact with the basal lamina in the OA regions, and only three of 407 did so in the NI regions. In the $\mathrm{NA}$ and OI regions, $6 \%$ and $4 \%$ of the cell processes made contact, respectively. However, the extent of contact was greater in the NA than in the OI region.

After 4-hr incubation, NA regions had about the same proportion of processes contacting the basal lamina; and, as a group, they made about the same or slightly less contact. The NI regions showed a great increase in the proportion of processes contacting the basal lamina, but they made less extensive contact than was seen prior to incubation. Only three out of 518 cell processes in the $\mathrm{OA}$ region had made direct contact with the basal lamina after incubation; but each of the three made substantial laminar contact. The OI regions increased both the proportion of processes making contact and the extent of that contact.

\section{Proximity of cell bodies to the basal lamina}

More cell bodies fell within the measured area subjacent to the nasal region than were seen in the oral one (Table 3). Cell bodies were markedly closer to the basal lamina of the NA segments than to the lamina of their inactive counterparts. Following incubation, the proportion of the mesenchymal area covered by cell bodies decreased in the nasal active area to that seen in the inactive one at $0 \mathrm{hr}$, while the latter showed no change. Both oral regions increased the proportion of their area covered by cell bodies during the incubation period.

\section{Changes in mesenchymal cell configurations with incubation time}

Table 4 summarizes these changes. No changes in numbers of cell processes were observed in the nasal regions. In the NA region, however, cell process size, distance from the basal lamina, and amount of area covered by cell bodies decreased with incubation time. A slightly smaller proportion of cell processes contacted the basal lamina after incubation, and they made less contact

Fig. 1 The epihelial-mesenchymal interface of nasal active (A), nasal inactive (B), oral active (C), and oral inactive (D) specimens prior to incubation. Arrowheads, $\sim 20$-nm filaments; slender arrows, (TAPM); open arrows, collagen. $\times 20,000$.
TABLE 2. Proportion of cell processes contacting the lamina densa*

\begin{tabular}{llllll}
\hline \multirow{2}{*}{$\begin{array}{l}\text { Incubation } \\
\text { time }(\mathrm{hr})\end{array}$} & \multicolumn{2}{c}{ Nasal $(\%)$} & & \multicolumn{2}{c}{ Oral $(\%)$} \\
\cline { 2 - 3 } \cline { 5 - 6 } \cline { 5 - 6 } & Active & Inactive & & Active & Inactive \\
\hline 0 & $19 / 318$ & $3 / 407$ & & $0 / 407$ & $23 / 610$ \\
& $(6)$ & $(0.7)$ & & $(4)$ \\
& $13 / 277$ & $11 / 129$ & & $3 / 518$ & $15 / 242$ \\
& $(5)$ & $(9)$ & & $(0.6)$ & $(6)$ \\
\hline
\end{tabular}

* No. cell processes contacting lamina densa/total No. of cell processes (\% cell processes making contact).

TABLE 3. \% area covered by cell bodies

\begin{tabular}{lccccc}
\hline \multirow{2}{*}{$\begin{array}{l}\text { Incubation } \\
\text { time (hr) }\end{array}$} & \multicolumn{2}{c}{ Nasal (\%) } & & \multicolumn{2}{c}{ Oral (\%) } \\
\cline { 3 - 3 } \cline { 5 - 6 } & Active & Inactive & & Active & Inactive \\
\hline 0 & 8 & 4 & 2 & 3 \\
4 & 5 & 4 & 4 & 7 \\
\hline
\end{tabular}

with it than seen at $0 \mathrm{hr}$. In contrast, NI regions showed no change in distance to the basal lamina or area covered by cell bodies. Cell-process size increased in the NI regions, as did the proportion of processes contacting the basal lamina. However, the extent of basal laminar contact decreased.

$O A$ regions showed decreased numbers of cell processes and increased distance of the processes from the basal lamina, as well as an increased area covered by cell bodies. The number of processes contacting the basal lamina increased from zero out of 457 to three out of 518, and the extent of their contact increased; but such contact must still be considered negligible. OI had about the same number of smaller cell processes which were farther from the basal lamina than at the outset. A larger fraction of the processes made substantially greater contact with the basal lamina. The area covered by cell bodies also increased.

\section{Comparison with controls}

Table 5 summarizes the differences between these CHLR-treated specimens and controls. CHLR treatment resulted in a greater number of smaller cell processes in three of the four regions examined: NA, NI, and OA. The OI regions had slightly fewer processes of about the same size distribution as were seen in controls. The distance between the cell processes and the basal lamina was unchanged in NA and OI regions and reduced in NI and OA regions. CHLR treatment had little or no effect on the proportion of cell processes which made contact 

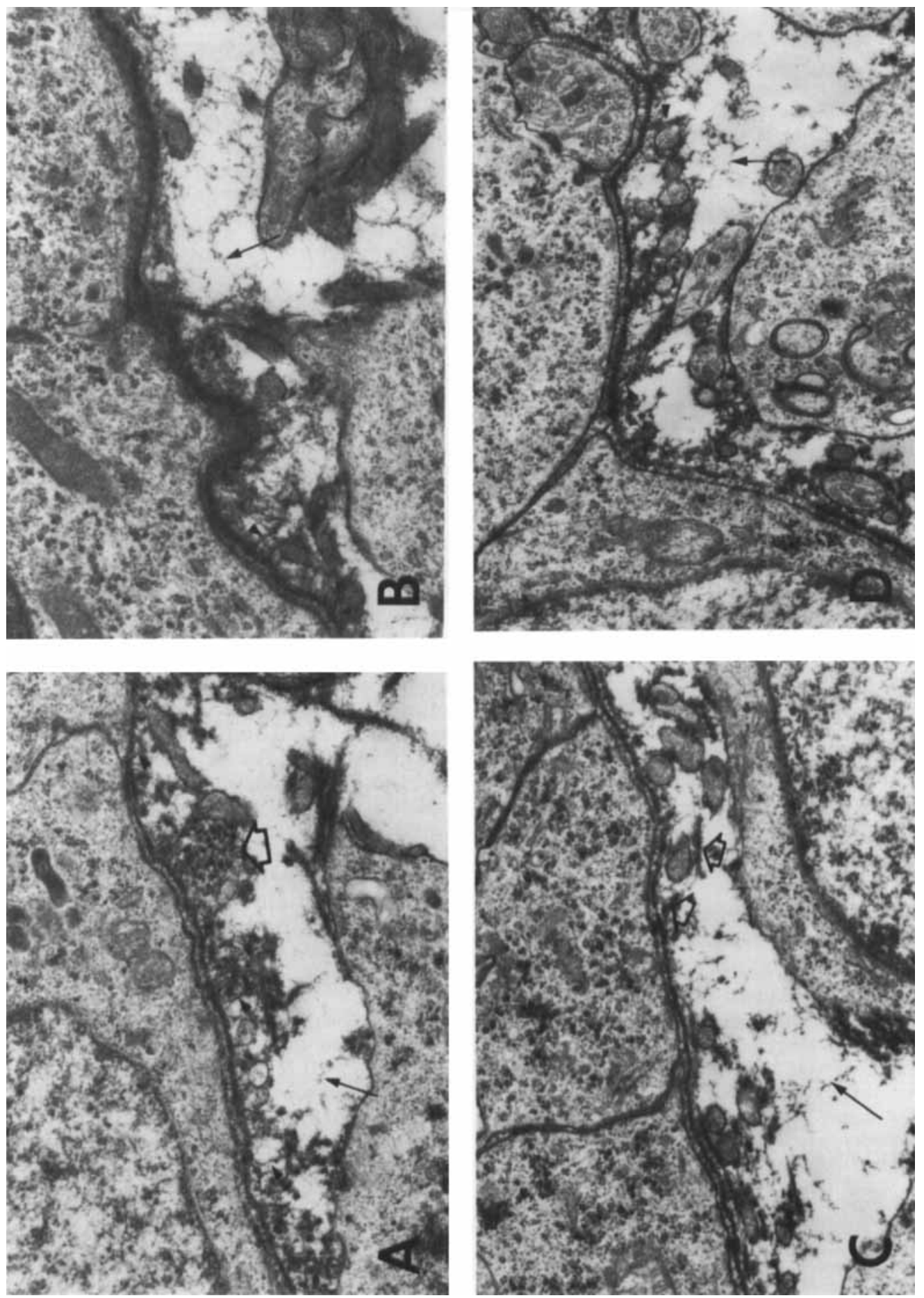
$\begin{array}{llll}\text { NA } & \text { NI } & \text { OA } & \text { OI }\end{array}$

\section{0 hrs}
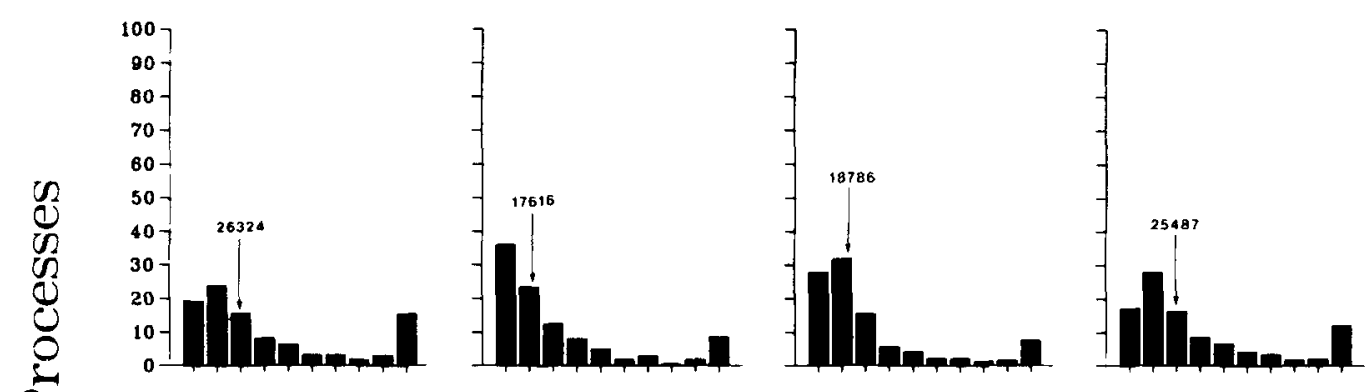

\section{4 hrs}
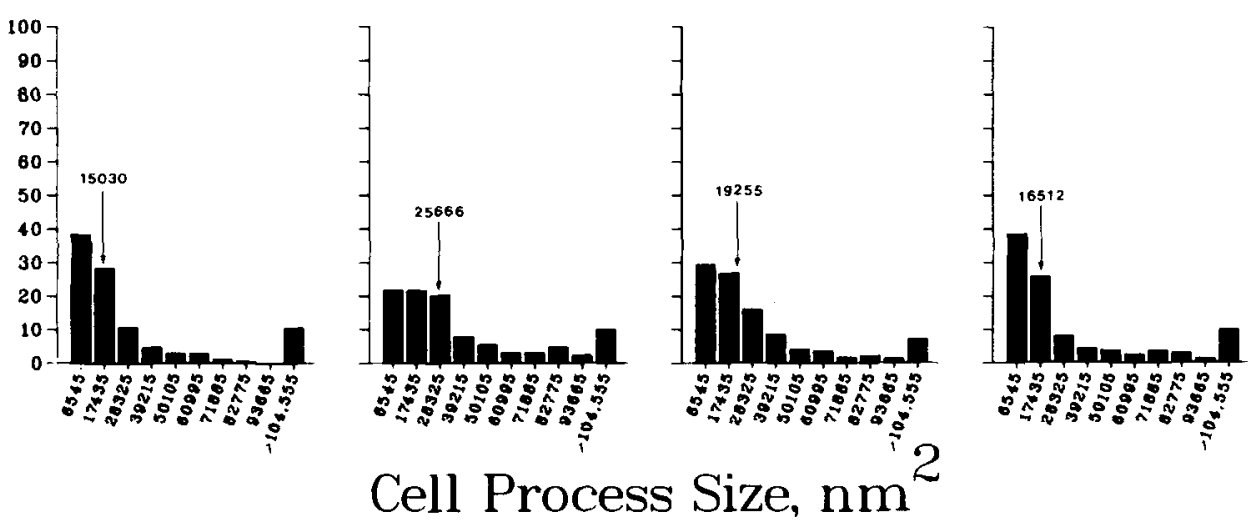

Fig. 3. Cross-sectional size distribution of mesenchymal cell processes prior to and after $4 \mathrm{hr}$ incubation. Median values are indicated by arrows. NA, nasal ac-

with the basal lamina in NA, NI, or OI regions; but it prevented any cell processes in the OA region from making contact. NA and NI regions showed considerably greater contact with the basal lamina than did their control counterparts, while OA and OI displayed considerably less. The area covered by cell bodies was increased in the NA region, but was decreased in the other three, particularly in the OA.

After 4-hr incubation, the number of cell processes had not changed in either NA or NI regions; however, the cell-process density was now somewhat less than that seen in

Fig. 2. The epithelial-mesenchymal interface of the four regions after $4 \mathrm{hr}$ incubation: (A) nasal active; (B) nasal inactive; (C) oral active; and (D) oral inactive. Arrowheads, $-20 . \mathrm{nm}$ filaments; slender arrows (TAPM); open arrows, collagen. $\times 20,000$. tive; NI, nasal inactive; $\mathrm{OA}$, oral active; OI, oral inactive. Sample sizes are given in Table 2.

NA regions of incubated controls and more than in NI regions of controls. Although the number of cell processes in the OA segments had decreased with incubation, the density remained slightly higher than controls. Cellprocess density in the OI regions was the same in CHLR-treated and control specimens. Cell-process size was reduced in all regions as compared to controls, but more so in the the NA and OI regions. Distance from the cell processes to the basal lamina was decreased in the nasal regions of CHLRtreated individuals, but increased in the oral ones. Three of the four areas, NA, NI, and OA, had substantially less area covered by cell bodies, while OI had more. Cell processes in the nasal regions made proportionally more contact with the basal lamina than in controls, while processes in the oral regions made less. The contacting cell processes in 
NA

\section{$0 \mathrm{hrs}$}

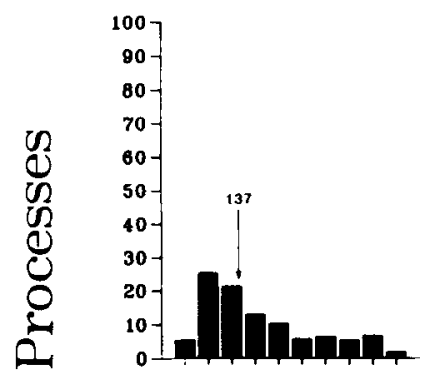

\section{4 hrs}

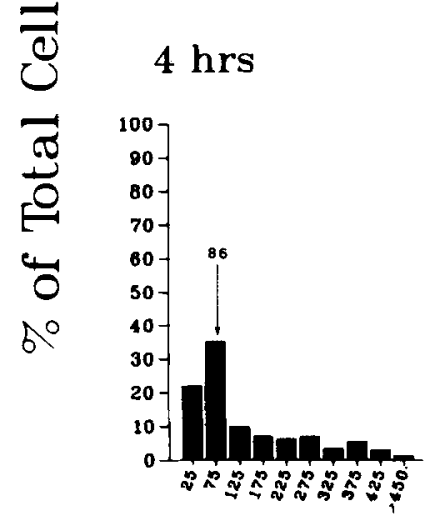

NI
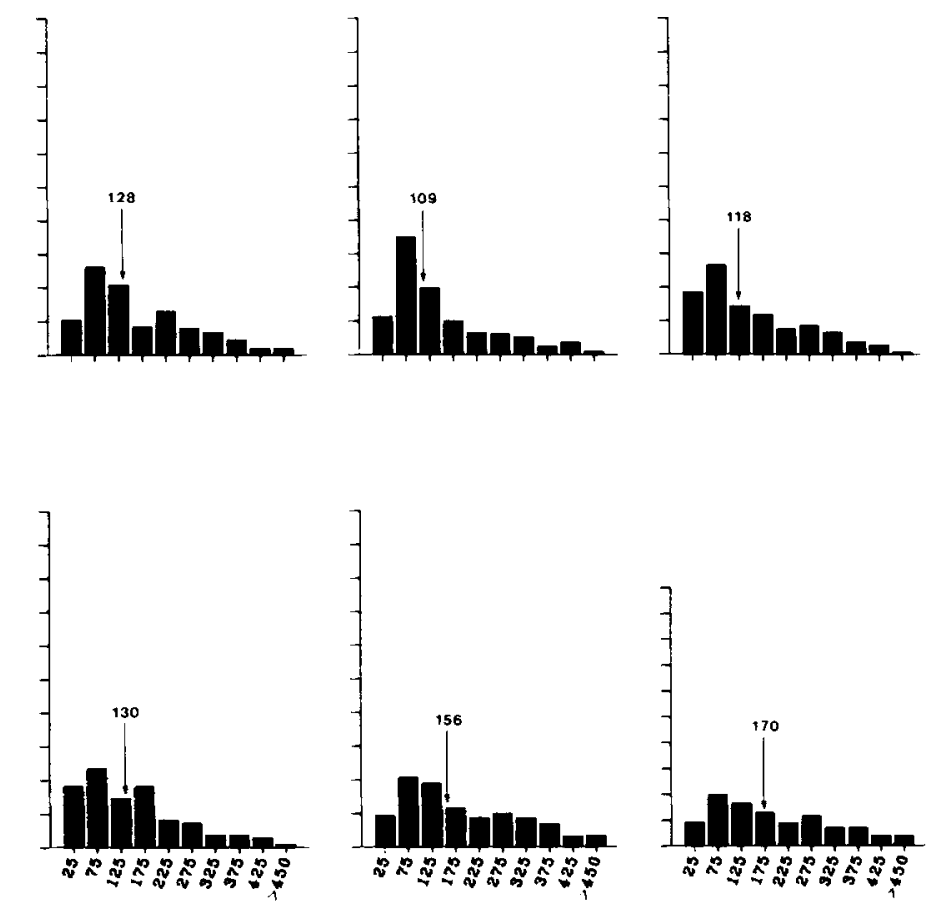

OA

OI
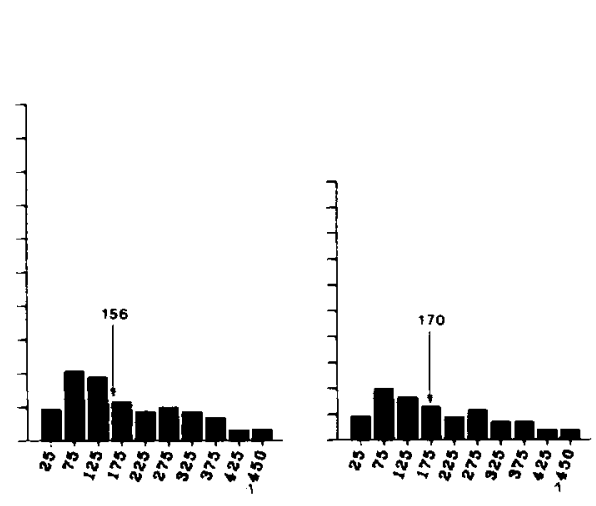

\section{Distance to Basal Lamina ( $\mathrm{nm}$ )}

Fig. 4. Distribution of distance from cell processes to the basal lamina. Median values are indicated by arrows. NA, nasal active; NI, nasal inactive; $\mathrm{OA}$, oral

$\mathrm{NA}$ and NI regions made less extensive contact than did those of controls. Only three out of 518 cell processes made contact in the $O A$ region, but each made more contact than the median contact made by control cell processes. The extent of contact made in the OI region did not differ from that of controls.

\section{DISCUSSION}

The alterations in extracellular matrix components induced by CHLR treatment resulted in quantifiable, region-specific differences in mesenchymal cell relationships to the basal lamina. The divergence of response to CHLR treatment between nasal and oral regions was most dramatic in the extent of contact made by cell processes. CHLR greatly enhanced the extent of contact made by cell processes in the nasal regions, while substantially reducing it in the oral ones. A concom- active; OI, oral inactive. Sample sizes are given in Table 2.

itant increase in proximity of cell bodies to the basal lamina was observed only in the NA regions; the others, particularly the oral ones, moved their cell bodies farther from the lamina. Dichotomies between active and inactive segments of each region were also apparent. Interestingly, mesenchymal cells in the NI and OA regions were often seen to behave similarly.

Extracellular matrix is known to play a role in cell morphology (see Trelstad, 1984, for review). This is exemplified by the fact that CHLR-induced reduction in size of the hyaluronate and chondroitin sulfate molecules resulted in more, smaller cell processes extending from mesenchymal cells immediately subjacent to the basal lamina in three of the four regions examined. Ultrastructural examination of CHLR-treated specimens indicated that the TAPM associated 
NA

NI

$\mathrm{OA}$

OI

\section{0 hrs}

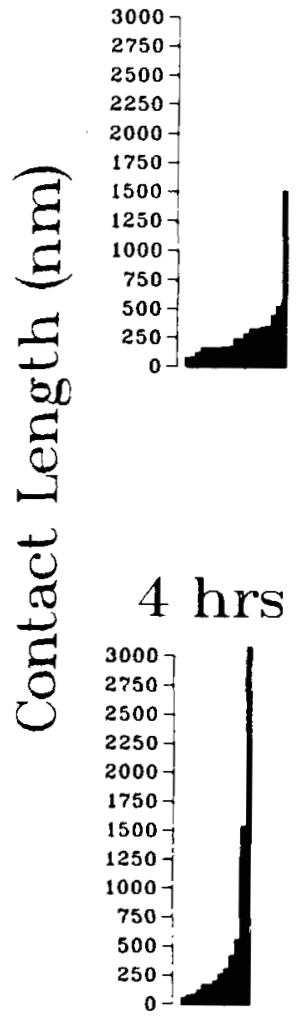

Fig. 5. Extent of contact of each cell process with the lamina densa. Each bar represents the contact made by one cell process. The number of bars shown is the total
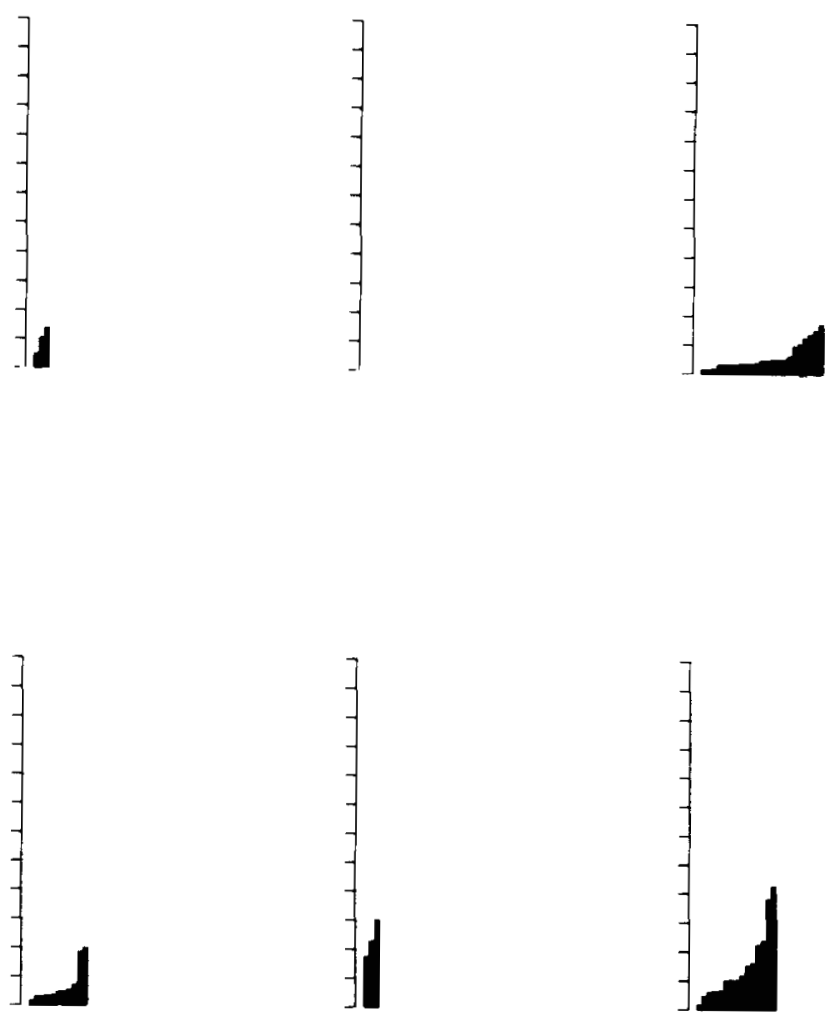

number of cells processes making direct laminar contact. Sample sizes are: $0 \mathrm{hr}$ : NA, $n=19 ; \mathrm{NI}, \mathrm{n}=3 ; \mathrm{OA}, \mathrm{n}=0$; OI, $n=23.4 \mathrm{hr}: \mathrm{NA}, \mathrm{n}=13 ; \mathrm{NI}, \mathrm{n}=11 ; \mathrm{OA}, \mathrm{n}=3 ; \mathrm{OI}, \mathrm{n}=15$.

TABLE 4. Changes* in mesenchymal cell configurations after 4-hr incubation

\begin{tabular}{|c|c|c|c|c|}
\hline & \multicolumn{2}{|c|}{ Nasal } & \multicolumn{2}{|c|}{ Oral } \\
\hline & Active & Inactive & Active & Inactive \\
\hline \multicolumn{5}{|l|}{ Changes in } \\
\hline No. CP/unit areal & 0 & 0 & $\ldots$ & 0 \\
\hline CP size & -- & ++ & 0 & -- \\
\hline Distance to $\mathrm{BL}^{1}$ & -- & 0 & ++ & $+t$ \\
\hline Area covered by cell bodies & - & 0 & + & + \\
\hline \multicolumn{5}{|l|}{ BL, Contact } \\
\hline Proportion of CP contacting BL & - & $+t+t$ & $\mathrm{n}$ & $+t$ \\
\hline $\begin{array}{l}\text { Change in median contact } \\
\text { length }\end{array}$ & - & $\cdots-$ & $n$ & +++ \\
\hline $\begin{array}{l}\text { Proportion of CP making greater } \\
\text { contact than maximum seen at } \\
0 \mathrm{hrs}\end{array}$ & $\begin{array}{l}2 / 13 \\
(15 \%)\end{array}$ & $\begin{array}{l}2 / 11 \\
(18 \%)\end{array}$ & $\mathrm{n}$ & $\begin{array}{l}4 / 15 \\
(27 \%)\end{array}$ \\
\hline
\end{tabular}


TABLE 5. Differences* between chlorcydizine (CHLR)-treated and controls before and after incubation

\begin{tabular}{|c|c|c|c|c|}
\hline & \multicolumn{2}{|c|}{ Nasal } & \multicolumn{2}{|c|}{ Oral } \\
\hline & Active & Inactive & Active & Inactive \\
\hline \multicolumn{5}{|l|}{$0 \mathrm{hr}$} \\
\hline Number CP/unit area & + & $+t+$ & $++t$ & - \\
\hline CP size & - & -- & - & 0 \\
\hline Distance to $\mathrm{BL}^{1}$ & 0 & -- & - & 0 \\
\hline $\begin{array}{l}\text { Area covered by cell bodies } \\
\text { BL contact }\end{array}$ & ++ & - & ---- & -- \\
\hline Proportion CP contacting BL & 0 & 0 & n & + \\
\hline Difference in median contact & +++ & +++ & $\mathrm{n}$ & ---- \\
\hline \multicolumn{5}{|l|}{$4 \mathrm{hr}$} \\
\hline Number CP/unit area & - & ++ & + & 0 \\
\hline CP size & -- & - & -- & --- \\
\hline Distance to BL & -- & - & $+t$ & +++ \\
\hline Area covered by cell bodies & -- & -- & -- & + \\
\hline \multicolumn{5}{|l|}{ BL contact } \\
\hline Proportion CP contacting BL & + & $+++t$ & a & - \\
\hline Difference in median contact & - & --- & a & 0 \\
\hline
\end{tabular}

*Changes are given as variations of CHLR-treated from controls. Increases $=+$; decreases $=-$. Amount of change: $0=<10 \% ;+$ or $-=10-25 \% ;++$ or $--=26-50 \%$; ++ or $---=51-75 \%$; ++++ or $---->76 \%$.

$\mathbf{n}=$ CHLR had no CP contacting, whereas $3.2 \%$ of control cell processes made contact. ${ }^{a}=$ After incubation only three of 518 cell processes made contact, but each made extensive contact.

${ }^{1} \mathbf{C P}=$ cell processes; $\mathbf{B L}=$ basal lamina

with the lamina densa after incubation was prominent in all four regions, but somewhat more so in the active ones. It is possible that the TAPM was new, intact glycosaminoglycans synthesized during the 4 -hr incubation period. Alternatively, the difference in appearance of the TAPM observed between control and CHLR-treated specimens may be the result of the smaller glycosaminoglycan molecules interacting wth one another and the fixative. The long, unbanded, $\sim 20-\mathrm{nm}$ filaments appear to be structurally unchanged by CHLR treatment, but they do seem to be more obvious. The distribution of the $\sim 20$ $\mathrm{nm}$ filaments does not seem to correlate with any particular region or mesenchymal cell configuration. As they seem relatively unaffected by CHLR treatment, it seems possible these filaments may be fibronectin or an unbanded form of collagen.

Alteration of glycosaminoglycans changes the ability of mesenchymal cells to make close contact with the lamina densa and to increase the extent of that contact during incubation. This might be a factor in the CHLR-induced failure of the palatal shelves to reorient. Whether these effects are only on the extracellular matrix (including the basal lamina) and the mesenchymal cells are merely responding to those changes, or whether, by altering the molecular configuration of cell coat and extracellular molecules, the internal cytoskeletal arrangement of the mesenchymal cells is in turn changing their functional state, cannot be determined. Regional effects of CHLR are probably not based principally on temporal differences in synthesis or degradation of glycosaminoglycans. The presence of CHLR in the fetal enviroment during the entire period of palatogenesis prior to death argues against this. Rather, the present results support the hy. pothesis that the epithelial-mesenchymal interface and the immediately subjacent zone of the nasal and oral regions, as well as their active and inactive segments, may be constitutively different. Mesenchymal cell-basal lamina relationships in each region differ qualitatively as well as in the magnitude of their response to CHLR. Further examination of these regions will be necessary to understand more of the role of epithelialmesenchymal relationships in palatal reorientation.

\section{ACKNOWLEDGMENTS}

This work was supported by NIH-NIDR grants DE02774 and 5K0400104 to LLB.

\section{LITERATURE CITED}

Bernfield, M., S.D. Banerjee, J.E. Koda, and A.C. Rapraeger 1984 Remodeling of the basement membrane as mechanism of morphogenetic tissue interaction. In: The Role of Extracellular Matrix in Development. R.L. Trelstad, ed. Alan R. Liss, New York, pp. 545-572.

Brinkley, L. 1980 In vitro studies of palatal shelf elevation. In: Current Research Trends in Prenatal Cranio- 
facial Development. R.M. Pratt and R.C. Christiansen, eds. Elsevier/North-Holland New York, pp.203-220.

Brinkley, L. 1984 Changes in cell distribution during mouse secondary palate closure in vivo and in vitro. I. Epithelial cells. Dev. Biol., 102: 216-227.

Brinkley, L. 1986 Changes in mesenchymal cell-basal lamina relationships preceding palatal shelf reorientation in the mouse. Am. J. Anat., 176:367-378.

Brinkley, L., and F. Bookstein 1986 Cell distribution during mouse secondary palate closure. II. Mesenchymal cells. J. Embryol. Exp. Morphol. (in press)

Brinkley, L., and M. Vickerman 1982 Effects of Chlorcyclizine-induced alterations of glycosaminoglycans on mouse palatal shelf elevation in vivo and in vitro. J. Empryol. Exp. Morphol. 69:193-213.

King, C.T.G. 1963 Teratogenic effects of meclizine hydrochloride in the rat. Science, 141:35-355.

King, C.T.G., S.A. Weaver, and S.A. Narrod 1965 Antihistamines and teratogenicity in the rat.
J Pharmacol. Exp. Ther., 147:391-398.

Lewis, C., L. Thibault, R. Pratt, and L. Brinkley 1980 An improved culture system for secondary palatal elevaton. In Vitro, 16:453-460.

Pratt, R.M., J. Goggins, A. Wilk, and C. King 1973 Acid mucopolysaccharide synthesis in the secondary palate of the developing rat at time of rotation and fusion. Dev. Biol 32:230-237.

Singley, C., and M. Solursh 1980 The use of tannic acid for the ultrastructural visualization of hyaluronic acid. Histochemistry, 65:93-102.

Singley, C., and M. Solursh 1981 The spatial distibution of hyaluronic acid and mesenchymal condensation in the embryonic chick wing. Dev. Biol., 84:102-120.

Trelstad, R., ed. 1984 The Role of Extracellular Matrix in Development. Alan R. Liss, New York, 643 pp.

Wilk, A., C.T.G. King, and R.M. Pratt 1978 Chlorcyclizine induction of cleft palate in the rat: Degradation of palatal glycosaminoglycans. Teratology, 18:199-210. 